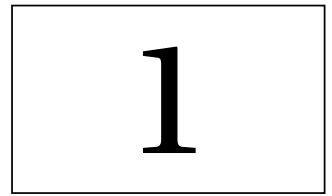

\title{
104 Driscoll
}

Avenue

The smoky smell of cooking bacon drifted down the hallway of I04 Driscoll Avenue, up three stairs, around a bend, and through Missy's barely cracked door to tickle her nose. Twelve feet plus three feet plus one and a half feet equals the distance the scent of bacon just traveled from the kitchen. Missy Maker's brain calculated, as her mouth watered, before she was even fully awake. She let the smell of bacon pull her up into a sitting position and then lead her down the stairs and into her family's kitchen. If G-ma cooks the whole pound ... Fifteen slices in one pound of bacon divided by three people, means at least five slices for me.

G-ma stood with her back toward the counter. She was busy working over the stove, a spatula in one hand and an oversize mug, filled with black coffee and featuring a photo of Missy and her sister, Molly, both smiling widely, in the other. G-ma moved expertly between the frying pan and griddle, her bright blue eyes in stark contrast to her black and silver hair. Missy imagined purple streaks atop G-ma’s spiky ‘do. 

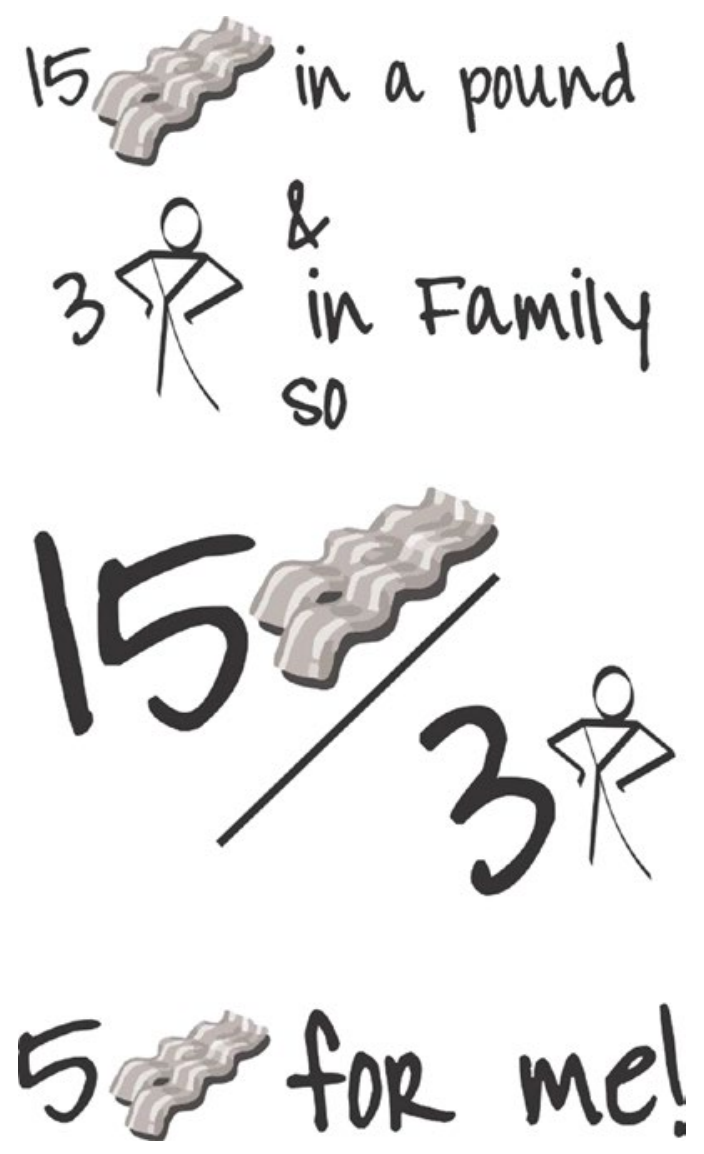

Bubbles exploded from the tops of the perfect pancake spheres. Missy thought of her favorite ratio- the diameter of a circle to the circumference of a circle-and how it resulted in the irrational and lovely number called pi. In a haze of bacon smoke, the elegant equation for the area of a circle, pi $r$-squared, seemed to float about the stove as G-ma adroitly flipped each pancake over. Just as it was done to crispy perfection, G-ma swiftly removed the bacon strips from the frying pan to a paper-towel covered plate.

“Good morning! Miss Melissa Merry Maker!" G-ma sang out noticing Missy watching her prepare breakfast. Then, as if reading Missy's thoughts, G-ma said, "I cooked only six slices of bacon, dearie. And six pancakes. That's two apiece of each." G-ma winked at Missy who sidled up to the kitchen peninsula and sat on a bar stool. 
As Missy watched her grandmother cooking breakfast, she felt an odd weight on her head. She raised her hand and touched her hair. She felt at once that she had forgotten to take down her ponytail before going to bed. Now, it sat askew, leaning to the right and creating a heavy sensation. Missy had unruly frizzy, blond hair. It was long, and Missy found the easiest way to manage it was to wrangle it into a bunch and to tie it tightly atop her head in various positions.

Missy pictured her head as a globe and overlaid a compass in her mind's eye. Zero degrees at the top; hair slipped to about 70 degrees. With determination, she grabbed her ponytail, quickly divided the hair between two hands and pulled and wrangled it up to the North Pole. Then Missy gave her hair a sharp tug pulling each handful in opposite directions to lock in the elastic band. Satisfied for now, Missy looked around the kitchen feeling more awake.

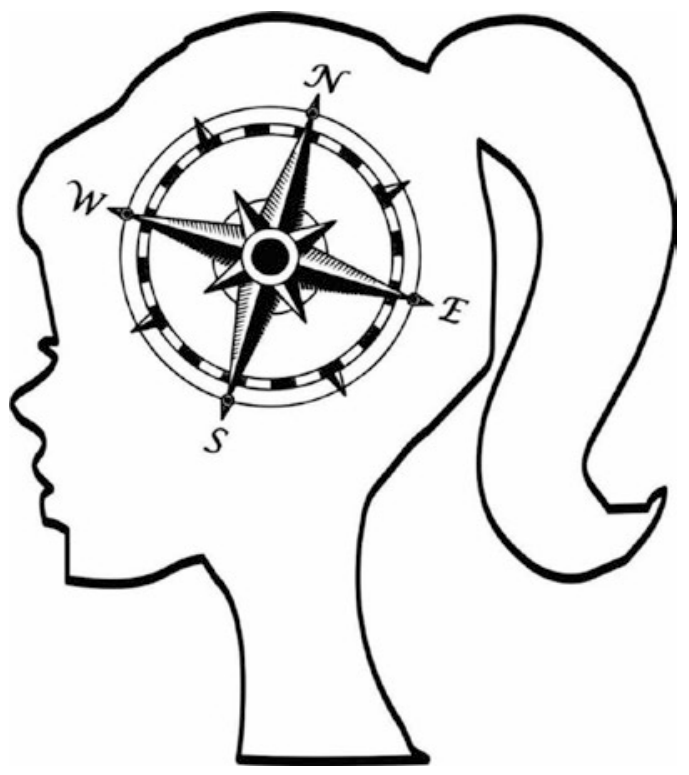

Missy's pet cat, Pi, arched its back and weaved in and out of the legs on Missy's stool. As a calico, Missy thought Pi was the most fashionable cat she knew! His brown and black striped fur and green eyes made him ready for any formal event; however, it was the perfectly round patch of black over white fur that encircled his left eye for which she had named him. Missy reached down to stroke Pi's fur.

"What's the occasion, G-ma?" Missy asked sitting back up and resting her chin in her hands. 
G-ma plated breakfast for Missy and herself then set down her spatula and delivered the plates to the peninsula. Then she walked to the refrigerator. She took out the maple syrup and butter, then said, "We're celebrating! TGIF: Thank G-ma, it's Friday!"

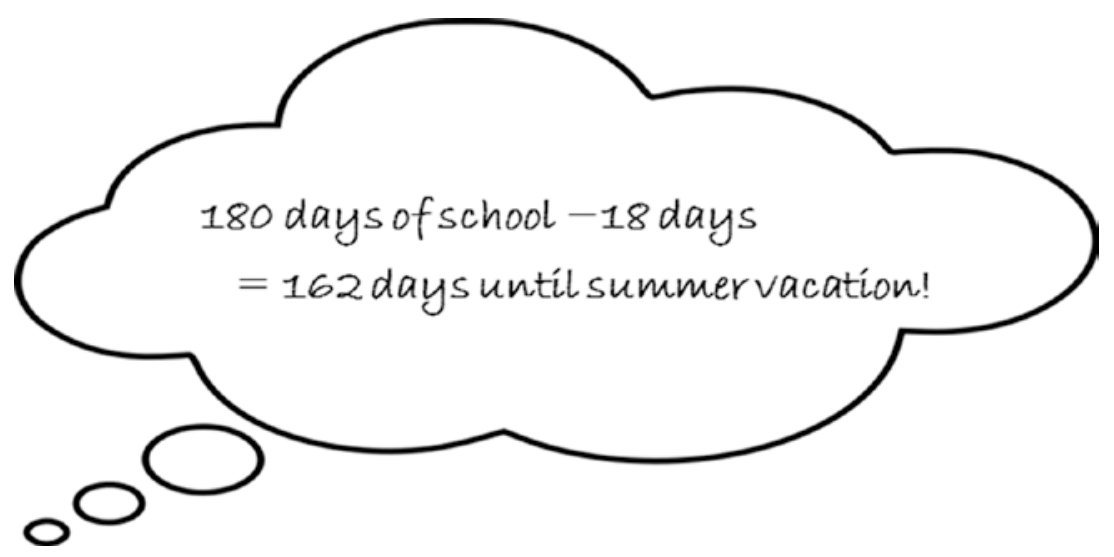

Missy laughed. Eighteen days of sixth grade down, one hundred and sixty-two left.

"Missy!" Mr. Maker called from the hall toward Missy's room.

"In here, Dad," Missy called back, "with G-ma! Breakfast is ready."

Mr. Maker walked into the kitchen and greeted his family. He was dressed as usual wearing a white button-down shirt with a colorful bow tie. Today it was green with yellow polka dots. He also wore his so-called dress-up jeans with black loafers. His black-rimmed glasses dangled precariously from his shirt pocket."Anyone seen my glasses?" he asked.

“Dad," Missy said, pointing,"they're hanging from your pocket!" Pi watched the exchange carefully and followed Missy's hand to stare up at Mr. Maker, too. He seemed just as incredulous as Missy that Mr. Maker could not find his glasses.

Mr. Maker patted his pocket. Reassured, he asked, "Did you sign up for any clubs last night?" He knew Missy had attended the Cherry Hill Academic Prep School's annual club fair with her best friend AJ, but they hadn't yet talked about it. "I heard from Ms. Jameson that there's a new math club this year and if they have enough students, they can compete in the Math Olympics," Mr. Maker explained. 
Ms. Jameson was Missy's math teacher, her neighbor, and her father's childhood friend. Forty-two minus twelve equals the length of their friendship. Sometimes it was awkward to have a teacher who your father knew so well. Ms. Jameson was the club advisor and had mentioned the math club to Missy a few times. Her teacher had really tried hard to recruit Missy and her friends to join at the club fair. Now, it seemed Ms. Jameson had also told her dad about it too.

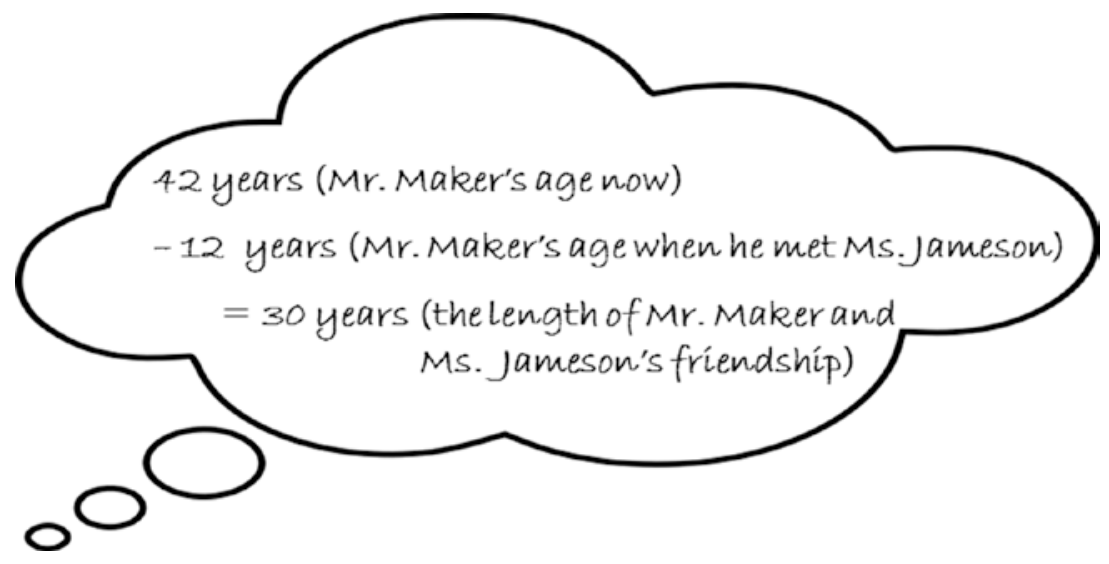

"I signed up for the fashion club with AJ," Missy responded.

G-ma poured steaming black coffee into a travel mug, screwed on the lid, and placed it on the edge of the counter for Mr. Maker.Then she plated the last of the pancakes and bacon and handed it to him.

Mr. Maker sipped his coffee and set the plate down next to Missy's. He raised his eyebrows at Missy who was watching him closely.

"Ha!" she said trying to change the subject away from joining the math club. "You drink too much coffee!"

"Well, I think you'd be a great addition to the math club," Mr. Maker joked."You see what I did there? Math club? Addition?!" He laughed and Missy rolled her eyes. "Think about it, kiddo," he said."You're great at math and the team could use your skills."

"Sure, Dad," Missy said, knowing that she would never join the math club. It was bad enough she had a brain that automatically invented math stories about everything she looked at! No way did she want her friends to know what a geek she really was. This year, she would shed her childhood nickname, "Missy-Math-Maker," and she would focus on girl stuff. The fashion club was just the ticket! She loved fashion and all the creative possibilities and she knew it would be time-consuming, maybe too time-consuming to do anything else! 
Mr. Maker took a gulp of his coffee then looked at his watch. He put his cup down and grabbed a napkin from the napkin holder on the peninsula. $\mathrm{He}$ placed one pancake on it; he snapped his bacon into four pieces and added that to the pancake, he topped that with a pat of butter and a drop of syrup, and finally the other pancake; then he rolled his pancake sandwich inside the napkin, swapped it with his glasses in his shirt pocket and grabbed his keys from the counter. He kissed Missy on the forehead before picking up his mug again.

"I want to hear more about this fashion club, kiddo. Have a gee-are-eight day!" he said tugging Missy's ponytail."See what I did there?" he winked and blew a kiss across the kitchen to G-ma."Early meeting. I'm off!"

G-ma returned the kiss by air mail then smiled at Missy.“Let's finish up, dearie," she said.

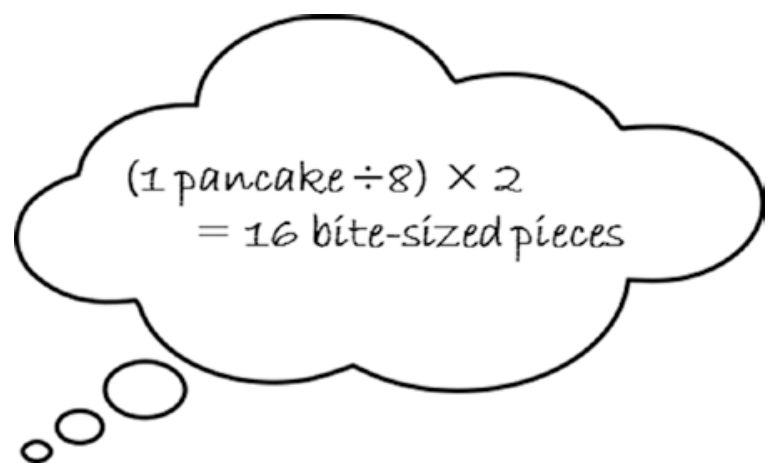

Missy cut her pancakes into quarters then eighths, and calculated how many bite-sized pieces she'd just made. One bite is one-sixteenth of my pancakes. She poured maple syrup over her whole plate drenching her pancake pieces and bacon slices. "Did Molly call yet?" she asked G-ma with a mouthful of food.

"Swallow before speaking, dearie. I was just about to check in with her," G-ma said reaching for the kitchen computer keyboard. Just as she clicked the enter key, she heard the familiar dong of a video call coming through.

"Molly!" Missy shouted and positioned herself in front of the screen.

"Good morning Miss Molly May Maker!" said G-ma, using a napkin to touch the screen to peck Molly's cheek as if she were kissing her."Smooch!" she said. "Hey, G-ma! Hey, Missy! Did Dad leave?” Molly asked.

"You just missed him," G-ma said. 
"Bummer. I wanted to share my news, but l'll send him an email later," Molly said. "You won't believe it! I won a scholarship to go to the Grace Hopper Celebration of Women in Computing!"

Missy wrinkled her nose and peered at her sister through the screen with a confused look on her face. She knew Grace Hopper had been an admiral in the U.S. Navy and an early computer scientist, but why was she having a celebration? "Is it a party?" Missy asked, "Can I come too?"

Molly had been telling G-ma about the program. "It's not a party. It's a conference where thousands of women and men get together and talk about technology! I'm so excited. l'll be counting down the days!"

"That's wonderful, Molly! We are so proud of you!" G-ma said."Before I retired, I attended a few Grace Hopper events myself! It's a great place to connect and network with folks from a variety of technology areas," G-ma told Molly.

"And maybe I can land a summer internship," Molly added.

G-ma and Molly chatted while Missy finished her breakfast. "Love you, Miss," Molly shouted to Missy as she ended the call."Let's catch up soon."

Missy missed having her sister at home. Ten weeks till Molly comes home for break is seventy days or...

Stop! Missy interrupted her thoughts. For a girl who was trying not to be a geek, the message sure hadn't made it to her brain. Missy rinsed her plate in the sink and loaded it into the dishwasher along with her fork and knife. Her mind was racing. How was she ever going to recreate her image as a regular girl if she couldn't even control her own thinking?

Pi pranced to the dishwasher and gave it a sniff. "Ready for breakfast, Pi?" Missy asked. "Tuna or salmon?" Pi wove his way through Missy's legs as Missy got out the can opener and pulled out a can of cat food from the cupboards above. Then she reached down and picked up Pi's dish. She quickly rinsed and dried it and then refilled it. She poured fresh water into his water bowl while $\mathrm{Pi}$ actively ignored her. With the bowls filled and replaced in their familiar location, Pi swished his tail and tucked into his own breakfast.

"Fifteen minutes till the bus comes," G-ma reminded Missy. Missy finished feeding $\mathrm{Pi}$ and washed her hands in the kitchen sink.

Fifteen divided by brushing teeth and dressing and walking to the corner to get the bus equals three minutes to brush, two minutes to walk, which leaves ten minutes to dress. Missy sprinted to the hallway bathroom and brushed her teeth. She ran up the stairs to her room and threw open the doors to her closet. Missy checked her smartphone calendar. "Friday is fun-in-the-sun day," the calendar reminded her. 


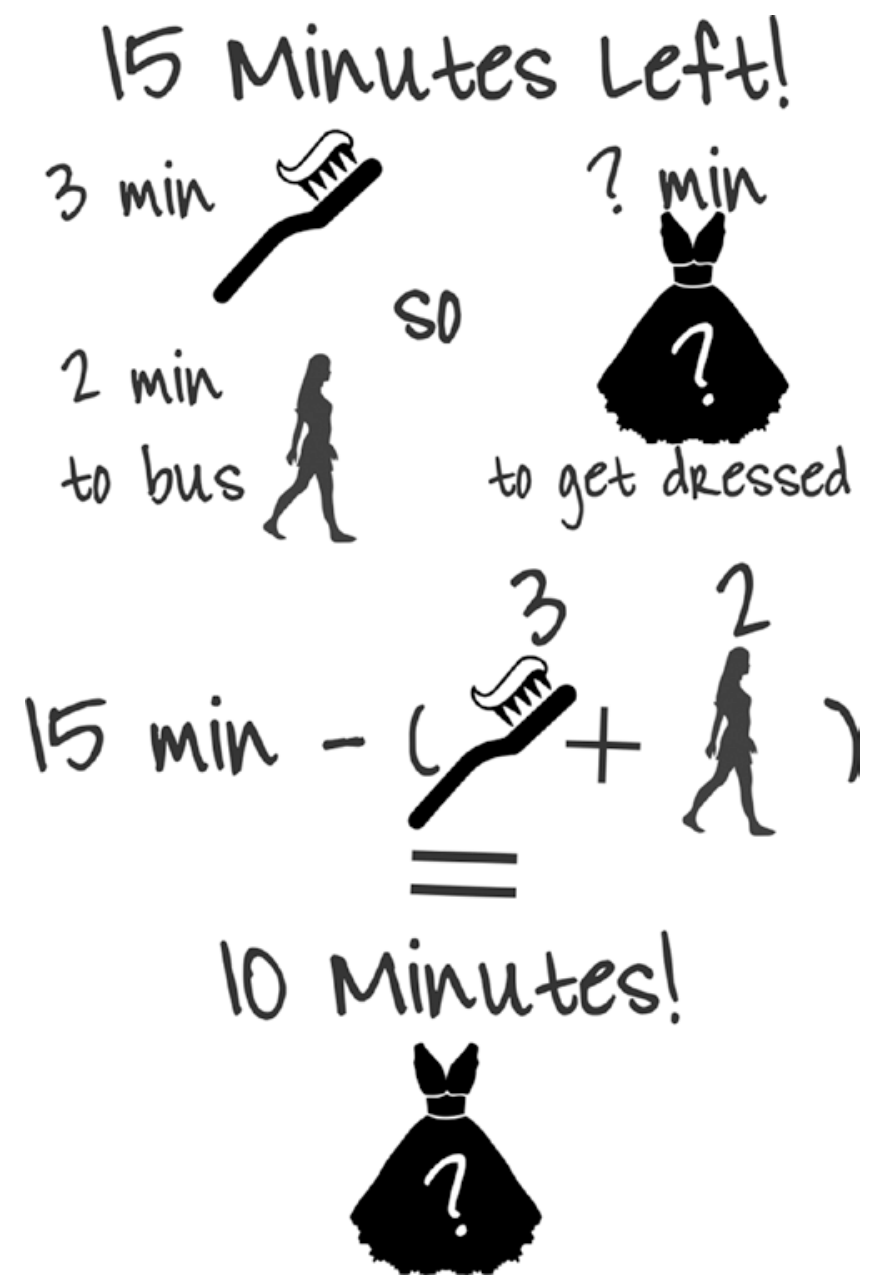

Missy and her best friend Andrea Jane Dupre, better known as "AJ," had sketched out a fashion calendar for every school day. They had sat down on Missy's bedroom floor and mapped out fashion themes for the first marking period of middle school. Each week had a general theme and every Friday had a specific outfit idea. They typed it all up and posted it online to share with their friends.

As Missy rushed to get ready, she pulled out denim shorts, which at one time had been her favorite jeans. When she had grown two inches over the summer, G-ma had insisted they go into the donations pile. On a lark, Missy cut them off at the knees and frayed the bottom two inches. Now her favorite jeans were her favorite shorts! Missy added a teal t-shirt bejeweled with a sparkly giant $M$ on the front. Next, from her dresser drawer, she took out two knee socks: one black and white striped and one teal with yellow stars. 
Shorts plus top plus sock plus coordinating sock equals one rocking outfit! Missy dressed quickly and stuffed her feet into her favorite black tennis shoes artfully splattered with reflective pink and orange paint.

She stopped by the full-length mirror in the corner of her room, re-tied her ponytail and put on a pair of teal and glitter cat-eye sunglasses, then she smiled, posed and snapped a selfie. She posted the photo with the hashtags OOTD (Outfit of the Day) and FITSD (Fun-in-the-Sun Day). Satisfied with her look, Missy headed out to catch her bus, shouting "Bye, G-ma," as she pushed through the spring-loaded front door that slammed shut behind her while she scanned her SocialMe feeds to see who else had posted an OOTD.

\section{MATH HACK: WHAT IS PI?}

$\mathrm{Pi}$ is an irrational number represented by this symbol from the Greek alphabet:

\section{$\boldsymbol{\pi}$}

To calculate pi, you simply divide the circumference of a circle by its diameter. This is also called a ratio. What's so awesome about pi is that it never changes. No matter how large or how small the circle, pi is always the same! Try it for yourself! You'll be amazed.

Here's a trick to help you remember the first digits in pi. Just count the number of letters in each of the words in this phrase: May I have a large container of coffee?

When you calculate pi, you will also see that the numbers never repeat or create a pattern. Many people round it down to just the first two decimal places. However, this is pi to its first 100 decimal places:

3.14159265358979323846264338327950288

4197169399375105820974944592307816

$4062862089986280348253421170679 \ldots$

\section{FUN FACT}

March 14 in the United States is celebrated as Pi Day because March is the third month of the year and this date is notated like this: 